\title{
ЭПИНЕКС В ДЕТСКОЙ ПРАКТИКЕ, ДЕЙСТВИЕ НА ЭМОЦИОНАЛЬНУЮ СФЕРУ
}

\author{
'Гашимзаде Н.Ф., ${ }^{1}$ Ибрагимова Э.А., ${ }^{2}$ Мамедов Э.Э. \\ 'Детский Психоневрологический Диспансер, Баку; \\ ${ }^{2}$ Азербайджан Медицинский университет, кафедра Общественного здоровья и организации \\ здравоохранения, Баку
}

Как известно проблема эмоциональных и когнитивных нарушений у детей в эпилепсии является одной из важных проблем, решением которой занимаются многие исследователи в области эпилептологии. В арсенале эпилептологов в последнее время появились противосудорожные препараты нового поколения, которые обладают рядом положительных свойств по отношению к препаратам старого поколения.

Целью нашей работы было исследовать положительные свойства препарата нового поколения - леветирацетама, который известен под торговой маркой - эпинекс. По данным литературы когнитивные нарушения занимают около $30-45 \%$ у детей, больных эпилепсией и 20-39\% больных, страдают тревожными расстройствами и депрессией. [1]. Как известно по химическому составу он близок к ноотропам, что делает его преимущественным препаратом для больных, с когнитивными нарушениями. Нас интересовало действие эпинекса на эмоциональную сферу детей.

Для поставленной цели мы исследовали 160 детей, в возрасте от 5- 17 лет. Все дети получали эпинекс. Мальчики и девочки составляли соответственно 92 и 78 человек. Исследование проводилось в течении 3 -х месяцев. Из исследуемых, 26 человека страдали логоневрозом, 17 человек были с диагнозом - миоклония. 56 с генерализованными приступами.,19 детей с диагнозом сложные фокальные припадки, у 42 - ночные пароксизмы. Эпинекс давался в дозах, начиная от 250 мг. Доза еженедельно увеличивалась и в среднем достигала 1000 мг. В зависимости от возраста ребенка, веса и поставленного диагноза. Доза эпинекса при заикании колебалась от 250 до 500 мг в сутки. И не смотря на малую дозировку давала положительный эффект в $37 \%$ случаях, т.е. полное прекращение заикания. В $75 \%$ случаях наблюдалась положительная динамика. В течение изучаемых месяцев в $66 \%$ у детей наблюдалось уменьшение частоты приступов. У 22\% прекращение приступов. При средней дозировке препарата 1000 мг в сутки. Особенно хороший эффект наблюдался у детей с мио клоническими приступами. В этом случае прекращение приступов возникало у 40\% детей. Необходимо отметить, что в тех случаях, когда не смотря на увеличение дозы эпинекса не наблюдалось урежение частоты приступов, мы использовали комбинированную терапию с препаратами другого ряда - депакин- вальпроевая кислота. И добивались урежение частоты приступов в 67\%. Особенно такая комбинация препаратов положительно действовала на детей с генерализованными припадками (10\%).

Для исследования тревожности и агрессивности использовались рисуночные тесты - несуществующее животное, для депрессии тест Гамильтона.

Все дети обследовались психологом до и после начала приема препарата. Для контрольной группы были выбраны дети с судорожными припадками и эпилепсией, принимающие другие препараты.

По результатам исследования до лечения тревожностью, страхами, нервозностью страдали 89,9\% всех исследуемых детей. В $35 \%$ случаях мы наблюдали значительное уменьшение тревоги у детей. Ни у одного ребенка не наблюдалось ухудшение эмоциональной сферы, в виде усиления 
тревожности или депрессии. Наоборот, психологами отмечалось, что дети стали менее агрессивными и более спокойными. Хотя в литературе мы встречаемся противоречивыми фактами по поводу действия леветирацетама на тревожность и агрес-

\section{ЛИТЕРАТУРА}

1. Cereghino J.J., Biton V., Abou-Khalil B. et al. Levetiracetam for partial seizures: results of a double-blind, randomized clinical trial // Neurology. 2000; 55: 236-242. сию у детей $[1,2]$.

Таким образом, в результате наших исследований мы рекомендуем применение препарата эпинекс у детей с эпилептическими припадками и имеющими нарушения в когнитивной и эмоциональной сфере.

2. Mazza M., Martini A., Mazza S. Effect of levetiracetam on psychiatric symptoms in adult epileptic patients // Epilepsia 2007; suppl 48;6;105.

\title{
EPINEKS - UŞAQ PRAKTIKASINDA TOTBIQİ, EMOSIONAL SFERAYA TOSIRI
}

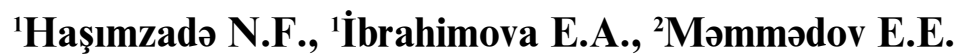

${ }^{1}$ Uşaq ruhi-asab dispanseri, Bakl;

${ }^{2}$ Azərbaycan Tibb Universiteti, İctimai sağlamlıq vo səhiyyənin təşkili kafedrası, Bakı

Tətqiqatın əsas məqsədi epineks preparatının uşaqlarda müxtəlif növ epileptik tutmalara, həmçinin epilepsiya xəstəliyində müşahidə olunan qorxu, təşviş və depressiv pozuntulara təsirini öyrənilməsi olmuşdur. Tətqiqat zamanı 5-17 yaşda olan 160 uşaqda epilepsiyanın müxtəlif formaları və epileptik tutma önü hallar 3 ay ərzində müayyinə olunmuşdur. Təyin olunmuşdur ki, epineks qəbulu zamanı uşaqlarda yaxşı dözümlülük müşahidə edilmiş,qorxu, təşviş və depressiyanı artırmamış, hətta $35 \%$ uşaqda oyanıqlılığı aşağı salmışdır.

\section{EPINEKS İN PEDİATRIC PRACTICE, THE EFFECT ON THE EMOTIONAL SPHERE}

\author{
${ }^{1}$ Hashimzade N.F., ${ }^{1}$ Ibragimova E.A., ${ }^{2}$ Mammadov E.E. \\ ${ }^{1}$ Child psycho neurological dispensary, Baku; \\ ${ }^{2}$ Azerbaijan Medical University, Department of public health and health organization, Baku
}

Purpose of the article was to study the effect of the drug epineks for different types of epileptic seizures in children, as well as its impact on anxiety and depressive disorders are very common in epilepsy. Was studied 160 children, aged 5 to 17 years, the various manifestations of epilepsy and convulsive, within 3 months. It was found that despite epineks well tolerated in children and increased the anxiety and depression that is available in children, and $35 \%$ even caused a decrease anxiety. 